Running head: PERCEIVED SUPPORT, EMOTIONAL EXHAUSTION, AND TURNOVER

Perceived Organizational Support, Emotional Exhaustion, and Turnover:

The Moderating Role of Negative Affectivity

\author{
Catherine Marchand \\ HEC Montréal \\ Management Department \\ 3000 chemin Côte Ste-Catherine, Montréal (Québec) \\ Canada H3T 2A7 \\ Email : catherine.marchand@hec.ca \\ Christian Vandenberghe, Ph.D. \\ HEC Montréal \\ Management Department \\ 3000 chemin Côte Ste-Catherine, Montréal (Québec) \\ Canada H3T 2A7 \\ Email : christian.vandenberghe@hec.ca
}


Running head: PERCEIVED SUPPORT, EMOTIONAL EXHAUSTION, AND TURNOVER

Perceived Organizational Support, Emotional Exhaustion, and Turnover: The Moderating Role of Negative Affectivity 


\begin{abstract}
Using principles from conservation of resources theory (Hobfoll, 1989), this study examined the time-lagged relationship between perceived organizational support (POS; measured at Time 1), emotional exhaustion (measured six months later), and turnover (measured one year after Time 1), and included negative affectivity (NA) as a moderator. Drawing upon a sample of employees from multiple organizations $(N=135)$, we found POS to be unrelated to emotional exhaustion but the latter to be negatively related to turnover. NA moderated the relationship between POS and emotional exhaustion and POS's indirect relationship to turnover, these relationships being stronger and positive at high levels of NA. Moreover, NA moderated the link between emotional exhaustion and turnover, this link being stronger and positive when NA was low. We discuss the relevance of conservation of resource theory as a useful framework for interpreting POS's effects.
\end{abstract}

Keywords: Perceived Organizational Support, Emotional Exhaustion, Turnover, Negative Affectivity, Conservation of Resources Theory. 


\section{Perceived Organizational Support, Emotional Exhaustion, and Turnover: The Moderating Role of Negative Affectivity}

In the last two decades, perceived organizational support (POS) has been the focus of much attention in the organizational behavior literature (Baran, Shanock, \& Miller, 2012; Rhoades \& Eisenberger, 2002). POS reflects employees' perception of "the extent to which the organization values their contributions and cares about their well-being" (Eisenberger, Huntington, Hutchison, \& Sowa, 1986, p. 504). Research has shown that POS emerges from a variety of antecedents, including work conditions, and distributive and procedural justice, and relates to a wide array of outcomes, such as organizational commitment, intention to stay, and employee performance (Loi, Hang-Yue, \& Foley, 2006; Rhoades \& Eisenberger, 2002; Riggle, Edmondson, \& Hansen, 2009; Wong, Wong, \& Ngo, 2012). Organizational support theory (e.g., Eisenberger et al., 1986; Rhoades \& Eisenberger, 2002) states that POS develops as a result of social exchange relationships with the organization (Baran et al., 2012; Blau, 1964; Cropanzano \& Mitchell, 2005) and instills a sense of obligation that leads to positive attitudes toward the organization and performance.

In the present study, we use Conservation of Resources (COR) theory (Hobfoll, 1988, 1989) as an alternative framework explaining POS's workings. COR theory has been developed to explain the stress process by focusing on the essential role of resources in stress reactions and burnout (Halbesleben, 2006; Hobfoll, 2011; Holahan, Moos, Holahan, \& Cronkite, 1999). Hobfoll (2002, p. 307) defined resources as "those entities that either are centrally valued in their own right (e.g., self-esteem, close attachments, health, and inner peace) or act as a means to obtain centrally valued ends (e.g., money, social support, and credit)". Following COR theory (Hobfoll, 1989, 2002), POS can be considered as a social resource because it would signal to employees that help is available during work completion. 
We contend that POS can act as a resource that ultimately leads to reduced turnover. We extend research on POS and turnover (e.g., Eisenberger, Stinglhamber, Vandenberghe, Sucharski, \& Rhoades, 2002; Rhoades \& Eisenberger, 2002; Stinglhamber \& Vandenberghe, 2003) by exploring the possibility that POS results in employees enjoying more resources that can be used for completing work duties more effectively, thereby reducing the risk of emotional exhaustion (which reflects one's feeling that emotional resources are drained [Halbesleben, 2006] or "overextended and depleted" [Maslach, Schaufeli, \& Leiter, 2001, p. 399]). Lower emotional exhaustion would in turn lead to reduced turnover. Thus, the present study fills an important gap in the POS literature by testing a neglected mediator of POS's effect on turnover, i.e., emotional exhaustion.

As a second objective, we investigate whether (a) POS's effect on emotional exhaustion and (b) emotional exhaustion's effect on turnover are moderated by negative affectivity (NA), which, to our knowledge, has not been examined in previous research. NA reflects a disposition towards experiencing negative emotions such as those expressed by adjectives as "depressed" or "fearful" (Watson, Clark, \& Tellegen, 1988) and involves a pessimistic interpretation of reality (Bowling, Hendricks, \& Wagner, 2008; Weiss \& Cropanzano, 1996). First, we argue that because they tend to perceive their environment negatively (Bowling et al., 2008), high-NA employees will experience the support from the organization (POS) in negative terms. That is, they will think support is not disinterested and that the organization shows support to force them to work harder on its behalf. Hence, we expect that among high-NA individuals POS will have stressful effects, resulting in more emotional exhaustion and ultimately increased turnover. Second, because both NA (Barsade, Brief, \& Spataro, 2003; Ng \& Sorensen, 2009) and emotional exhaustion (Wright \& Cropanzano, 1998) act as stress factors causing withdrawal, it is likely that they will substitute 
for one another and enter in a "compensatory" form of interaction. That is, we expect emotional exhaustion to exert a more significant and positive effect on turnover when NA is low (vs. high). By adopting a COR theory perspective on POS's workings and investigating its effects on emotional exhaustion and indirect relationship to turnover, this study intends to highlight a neglected aspect of POS, namely its central role in individuals' cycle of resource gains/losses and how this affects the turnover process. Moreover, we explore an important boundary condition, individuals' level of NA, a line of inquiry that remains largely neglected in POS research. In doing so, this study intends to demonstrate that providing support to employees (i.e., POS) is not a universal means of reducing psychological strain. Rather, POS may be counterproductive among high-NA employees and increase both emotional exhaustion and turnover likelihood. A final strength of the present study is that we rely on a 1-year, three-wave time-lagged study to examine our hypotheses. As much prior POS research has been crosssectional, this study's findings will represent a valuable extension to previous endeavors in this area. Our theoretical model is presented in Figure 1. In the next sections, we discuss our theoretical model and hypotheses.

\section{Hypothesis Development}

\section{POS, Emotional Exhaustion, and Turnover}

POS, which represents the organization's commitment to employees (Armeli, Eisenberger, Fasolo, \& Lynch, 1998), creates a sense of obligation towards the organization. Such felt obligation leads to a variety of positive attitudes and behavior benefitting the organization. For example, POS has been found to be positively related to organizational commitment, job satisfaction, and organizational identification (Allen, Shore, \& Griffeth, 2003; Riggle et al., 2009; Rhoades \& Eisenberger, 2002; Sluss, Klimchak, \& Holmes, 2008) and to be negatively associated with absenteeism, turnover intention, and voluntary turnover (Allen et al., 2003; 
Dawley, Houghton, \& Bucklew, 2010; Harris, Harris, \& Harvey, 2007; Hochwarter, Kacmar, Perrewe, \& Johnson, 2003; Maertz, Griffeth, Campbell, \& Allen, 2007; O’Neill, Vandenberg, Dejoy, \& Wilson, 2009; Rhoades \& Eisenberger, 2002).

In this study, we argue that POS can be conceived as a social resource that is available to employees as it carries the feeling of being esteemed, cared about, and rewarded by the organization (Eisenberger et al., 1986). All of these aspects constitute resources from the perspective of COR theory (Hobfoll, 1989). Furthermore, POS is indicative of a relationship with the organization that gives access to assistance when it comes to deal with demanding or stressful job conditions. Consistent with this view, research has demonstrated that POS is negatively associated with emotional exhaustion (e.g., Jawahar, Stone, \& Kisamore, 2007) and psychological distress (Ilies, Dimotakis, \& De Pater, 2010), and positively related to well-being (e.g., Armstrong-Stassen, 2004). These results are also in line with previous meta-analytic work reporting negative relationships between social support and emotional exhaustion (e.g., Crawford, LePine, \& Rich, 2010; Halbesleben, 2006; Lee \& Ashforth, 1996).

These results can be interpreted using COR theory principles. Essentially, the provision of support (e.g., POS) reduces the likelihood of finding complications at work and of being distracted while completing one's work. POS also improves the clarity of work expectations, and the understanding of norms. Moreover, as suggested by Armstrong-Stassen's (2004) study, it is likely that employees enjoying high POS engage more easily in control coping and refrain from using avoidance coping at work. Therefore, POS helps employees to work in an environment in which access to information and instrumental support are facilitated and/or to successfully cope with demanding situations (Armstrong-Stassen, 2004; Baran et al., 2012). All of this explains that POS should lead to a virtuous cycle of resource gains, as would be predicted by COR theory 
(Hobfoll, 1989, 2011), ultimately reducing the likelihood of experiencing emotional exhaustion over time. The following hypothesis summarizes the above reasoning and findings.

Hypothesis 1a: POS will be negatively related to emotional exhaustion.

We further argue that POS can lead to reduced turnover through lower emotional exhaustion. As described above, POS should first reduce the likelihood of experiencing emotional exhaustion over time. In turn, lower emotional exhaustion should result in reduced turnover, as suggested by several studies (Cordes \& Dougherty, 1993; Lapointe, Vandenberghe, \& Panaccio, 2011; Lee \& Ashforth, 1996; Swider \& Zimmerman, 2010). Indeed, people experiencing emotional exhaustion are likely to cope with the deprivation of resources at work through withdrawing from their environment (Maslach et al., 2001) in order to avoid further put their health in danger (Cole \& Bedeian, 2007; Hobfoll, 1989; Swider \& Zimmerman, 2010; Wright \& Cropanzano, 1998). In other words, leaving would represent a self-protective strategy. Taken together, these arguments suggest that POS will be negatively and indirectly related to turnover through emotional exhaustion. The above discussion leads to the following hypotheses: Hypothesis $1 b$ : Emotional exhaustion will be positively related to turnover.

Hypothesis 1c: Emotional exhaustion will mediate a negative relationship between POS and turnover.

\section{NA as a Moderator between POS and Emotional Exhaustion}

COR theory has highlighted the critical role of resources in the emergence of burnout and stress reactions (Halbesleben, 2006; Hobfoll, 2011; Holahan et al., 1999). Hobfoll (2002, p. 307) defined "resources as those entities that either are centrally valued in their own right (e.g., selfesteem, close attachments, health and inner peace) or act as a means to obtain centrally valued ends (e.g., money, social support, and credit)". Related research has also identified two main categories of resources: personal and social resources (Hobfoll, 1989, Hobfoll, Freedy, Lane, \& 
Geller, 1990; Hobfoll \& Lilly, 1993; Morelli \& Cunningham, 2012). Personal resources refer to personal characteristics (e.g., personality traits), energies (e.g., time spent to obtain pay), objects (e.g., a house), or conditions (e.g., job status). Personal resources help individuals to cope with stressful situations, facilitate resource acquisition, and influence individual perceptions, attitudes, and behavior (Barsade et al., 2003; Ng \& Sorensen, 2009). As such, these resources prevent burnout from occurring (Halbesleben, 2006, p. 1135). Social resources, such as social support, are defined as "those "social interactions or relationships that provide individuals with actual assistance or with a feeling of attachment to a person or group that is perceived as caring or loving, " (cf. Hobfoll \& Stokes, 1988; Hobfoll et al., 1990, p. 467). These resources play a central role in individuals' well-being as they give access to a wide spectrum of personal resources (e.g., by reinforcing positive aspects of the self; Halbesleben, 2006) and social resources (e.g., instrumental and emotional support) through relationships with others. Social resources emanating from the organization can be summarized in POS appraisals.

One well-established disposition that falls in the category of personal resources is the affectivity trait. However, this trait has two components, positive affectivity (PA; i.e., a tendency to experience positive emotions), and NA (i.e., a propensity to experience negative emotions) (Ng \& Sorensen, 2009; Watson et al., 1988), with the former representing a personal resource that relates negatively to stress variables and the latter being positively related to these outcomes (Connolly \& Viswesvaran, 2000, Ng \& Sorensen, 2009; Thoresen, Kaplan, Barsky, de Chermont, \& Warren, 2003). In this study, we specifically focus on NA as we anticipate that it will counteract the reducing effect of POS on emotional exhaustion. High-NA individuals feel more distress, anger, anxiety, and guilt (Watson \& Clark, 1984; Watson \& Pennebaker, 1989) than individuals with low NA. As they perceive a lack of (personal) resources to effectively deal 
with job demands, high-NA individuals experience increased stress and uncertainty (Spector, Zapf, Chen, \& Frese, 2000).

NA has also been studied as a moderator in a variety of investigations. For example, Stoeva, Chiu, and Greenhaus (2002) found that NA moderated the positive relationship between family stress and family interference with work in such a way that the relationship was stronger at high levels of NA, indicating that NA acted as a stress inducer. Similarly, Abraham (1999) found that NA moderated the relationship between emotional dissonance and job satisfaction, resulting in a more negative relationship when NA was high. Hochwarter, Perrewé, Hall, and Ferris (2005) looked at the moderating effect of NA in the relationship between felt accountability and job tension. The relationship between felt accountability and job tension was actually more positive when NA was high, suggesting that high-NA individuals perceived accountability as a stress factor. Finally, Iverson, Olekalns, and Erwin (1998) investigated the moderating role of NA in the relationship between coworkers' support and depersonalization (i.e., one dimension of burnout; Maslach et al., 2001). These authors found that high-NA individuals experienced more depersonalization as a result of co-worker support than their low-NA counterparts.

The above findings are particularly interesting because they convey converging evidence that NA acts as a stress enhancer (Abraham, 1999; Hochwarter et al., 2005; Spector et al., 2000, Stoeva et al., 2002). Iverson et al.'s (1998) study further demonstrates that even indications of support from the environment (i.e., co-workers) are experienced as stressful by high-NA individuals. Indeed, because high-NA individuals interpret their environment negatively (Bowling et al., 2008), they likely appraise POS as an indication that their organization want them to work harder and that support is not for free. In other words, high-NA individuals will react to POS by thinking that the organization has high expectations towards them, which may increase stress and anxiety (Baran et al., 2012). This suggests that these individuals would 
experience POS as an organizational demand rather than as an organizational resource (Mackey \& Perrewe, 2014). We thus posit that compared to their low-NA counterparts, high-NA employees will derive more emotional exhaustion over time from the supportive actions of the organization (as reflected in POS). This leads to the following hypothesis.

Hypothesis 2a: NA will moderate the relationship between POS and emotional exhaustion such that POS will be more strongly and positively related to emotional exhaustion at high (vs. low) levels of NA.

Following the argument presented above, we argue that NA will also moderate the indirect relationship between POS and turnover through emotional exhaustion. Indeed, the stronger emotional exhaustion experienced by high-NA individuals as a result of the anticipated interaction between NA and POS should incite them to find ways to protect themselves from further resource loss (Maslach et al., 2001). Given that emotional exhaustion tends to instill an avoidance coping style (Whitman, Halbesleben, \& Holmes, 2014), it is likely that the likelihood of withdrawing from the organizational context, hence leaving, would be increased (Allen et al., 2003; Lapointe, et al., 2011; Swider \& Zimmerman, 2010). Thus, a positive indirect relationship between POS and turnover through emotional exhaustion should be observed among high-NA individuals. Following Edwards and Lambert (2007), this represents a first-stage moderated mediation effect, wherein NA moderates the first path of the indirect link of POS to turnover (e.g., the link between POS and emotional exhaustion). We thus propose the following hypothesis.

Hypothesis $2 b$ : NA will act as a first-stage moderator of the indirect relationship between POS and actual turnover through emotional exhaustion such that this indirect relationship will be stronger and positive at high (vs. low) levels of NA.

\section{NA as a Moderator between Emotional Exhaustion and Turnover}


We argue that NA can also act as a moderator of the relationship between emotional exhaustion and turnover. Research has established that emotional exhaustion relates positively to employee turnover (e.g., Lapointe et al., 2011; Lee \& Ashforth, 1996; Swider \& Zimmerman, 2010). The rationale justifying this effect lies in the avoidance coping style that is typically associated with emotional exhaustion. That is, emotionally exhausted individuals tend to leave their organization because staying would cause further psychological damage and resource loss (Cole \& Bedeian, 2007; Maslach et al., 2001; Swider \& Zimmerman, 2010; Wright \& Cropanzano, 1998). In effect, evidence suggests that NA increases the likelihood of leaving (Thoresen et al. 2003; Zimmerman, 2008). Such positive relationship can be explained by the fact that NA involves a negative perception of oneself and the environment, and the resulting observation that those who perceive their work environment in negative terms are more inclined to leave their organization (Maertz \& Griffeth, 2004; Zimmerman, 2008). Following Watson, Wiese, Vaidya, and Tellegen's (1999) work, NA is the emotional/subjective component of the behavioral inhibition system, which has a neurobiological basis and acts as the driver of avoidance behavior in human life. High levels of NA would indicate the need to escape from unpleasant or aversive situations and would be fundamentally associated with avoidance behavior (e.g., turnover).

Our discussion leads to the observation that both emotional exhaustion and NA are linked to a withdrawal tendency. Emotional exhaustion would lead to withdrawal because it represents a psychological state of resource loss caused by a stressful environment (Halbesleben, 2006) while NA would cause withdrawal as it represents a dispositional tendency to escape from situations perceived to be aversive (Watson et al., 1999). Therefore, the two variables may substitute for one another and enter in what is called a compensatory form of interaction (Johnson, Groff, \& Taing, 2009). Thus, emotional exhaustion should exert a more significant and positive effect on 
turnover when NA is low rather than high. In effect, emotional exhaustion would not make much of a difference among people with high levels of NA as these people would be already inclined to think of leaving. In contrast, when NA is low, emotional exhaustion can have stronger effects on turnover, because there would be no dispositional basis among low-NA individuals to a priori think of leaving the organization. Note that a synergistic form of interaction is unlikely to happen as this would require that emotional exhaustion and NA have nonredundant and multiplicative effects on turnover (Johnson et al., 2009). Thus, we expect the relationship between emotional exhaustion and turnover to be stronger (and positive) when NA is low. As an extension of this, the indirect relationship between POS and turnover should be stronger and negative when NA is low. The latter prediction reflects a second-stage moderated mediation effect (Edwards \& Lambert, 2007), wherein NA moderates the second path of the indirect link of POS to turnover (e.g., the link between emotional exhaustion and turnover). The following hypotheses are thus proposed.

Hypothesis 3a: NA will moderate the relationship between emotional exhaustion and turnover such that emotional exhaustion will be more strongly and positively related to turnover at low (vs. high) levels of NA.

Hypothesis 3b: NA will act as a second-stage moderator of the indirect relationship between POS and actual turnover through emotional exhaustion such that this indirect relationship will be stronger and negative at low (vs. high) levels of NA.

\section{Method}

\section{Sample and Procedure}

We contacted a large sample of prospective participants from the network of our research team and invited them to participate in a study of job attitudes and perceptions. Email invitations included an introductory message describing the purpose of the study, ensured respondents that 
responses would be confidential, and contained a link to the Time 1 questionnaire (which comprised among others POS and NA items, and demographics [age, gender, and organizational tenure]). Respondents were asked to provide their private email addresses so they could be contacted six months later to complete the Time 2 questionnaire (namely including emotional exhaustion items). Six months after Time 2, participants were contacted to report their employment status (e.g., whether they stayed or left, and if they left, whether it was on a voluntary basis or not). This was the Time 3 survey. Data across the three surveys were matched via respondents' (private) email addresses. We chose a six-month interval between the surveys because this time separation is appropriate to disassociate cues across measurement occasions and allows forgetting responses to the previous survey (Podsakoff, MacKenzie, \& Podsakoff, 2012). Moreover, this timeframe has been found to be appropriate to capture the expected true effects of POS over time (e.g., Allen \& Shanock, 2013).

In total, 1150 prospective respondents were contacted for purpose of participation in the study. Among them, 277 (24.1\%) provided usable responses at Time 1. At Time 2, 163 usable surveys were obtained, for a 58.8\% response rate. Finally, at Time 3, 135 usable responses were collected, for an $82.8 \%$ response rate. To determine whether subject attrition across time led to non-random sampling, we tested whether the probability of remaining in the sample at Time 3 could be predicted by Time 1 (age, gender, organizational tenure, POS, and NA) and Time 2 (emotional exhaustion) variables (Goodman \& Blum, 1996). The criterion was a dummy-coded variable classifying respondents as stayers (i.e., those who responded at Time 3) vs. leavers (i.e., those who did not respond at Time 3). The logistic regression model was nonsignificant, $\chi^{2}(6)=$ $4.84, n s$, and none of the predictors was significant. This suggests that attrition across time was random in this study. 
Among respondents for whom complete data were available across measurement times $(N=$ $135)$, average age was 40.31 years $(S D=9.60)$, average organizational tenure was 8.93 years $(S D$ $=6.95)$, and $65.10 \%$ were female. Among these participants, $42.0 \%$ held managerial positions, with the remainder holding non-managerial positions; and 55.0\% worked in the private sector. Respondents worked in many different industries and occupations, including professional, scientific, and technical services (28.2\%), education (12.2\%), health and social services (16.8\%), manufacturing (12.2\%), retail and logistics (6.9\%), and finance, insurance, real estate and public administration $(11.5 \%)$.

\section{Measures}

All substantive variables except turnover were assessed using a 5-point Likert-type scale (1 = strongly disagree $; 5=$ strongly agree $)$. The study was conducted in French using scales translated and validated in French from original scales developed in English.

$\boldsymbol{P O S}$. To measure perceptions of support from the organization, we used an 8-item, French version (Stinglhamber \& Vandenberghe, 2004) of Eisenberger et al.’s (1986) POS scale (e.g., “The organization values my contribution to its well-being"; $\alpha=.92)$. Previous work has reported adequate psychometric properties for this translated version of the POS scale (Panaccio \& Vandenberghe, 2009; Vandenberghe, Bentein, \& Stinglhamber, 2004), which was found to incrementally predict affective organizational commitment, over and above measures of leadermember exchange and perceived group cohesiveness (Vandenberghe et al., 2004).

NA. A French version (Panaccio, Vandenberghe, \& Ben Ayed, 2014) of Watson et al.'s (1988) 10-item scale was used to measure trait NA (e.g., "hostile" and "ashamed", $\alpha=.88$ ).

Emotional exhaustion. To measure emotional exhaustion, we used a shortened 5-item version, validated in French (Lapointe et al., 2011), of Schaufeli, Leiter, Maslach, and Jackson’s 
(1996) Maslach Burnout Inventory-General Survey (e.g. "I feel emotionally drained by my work"; $\alpha=.87)$.

Turnover. We tracked respondents 6 months after the Time 2 survey to determine whether they had remained with their organization or left. Voluntary turnover was defined as a binary outcome (i.e., stay was coded as 0 , while voluntary turnover was coded as 1 ). The voluntary turnover rate between Time 2 and Time 3 was $7.4 \%$ in this study. Involuntary turnover cases were excluded from the sample.

Control variables. We controlled for age, gender, and organizational tenure in the analyses examining our hypotheses because these variables have been found to correlate with stress reactions (Bradley, 2007) and/or turnover (Griffeth, Hom, \& Gaertner, 2000).

\section{Results}

\section{Confirmatory Factor Analyses}

We first conducted confirmatory factor analyses on our data to examine the distinctiveness of the three multi-item variables of the study. LISREL 8.80 (Jöreskog, Sörbom, Du Toit, \& Du Toit, 2001) and a covariance matrix with the maximum likelihood method of estimation were used to run these analyses. Given the limited sample size $(N=135)$, we reduced the complexity of the measurement model by creating three parcels for POS and NA using the high-to-low loadings procedure suggested by Little, Cunningham, Shahar, and Widaman (2002). We used $\chi^{2}$ difference tests to compare the three-factor model to more parsimonious, nested models obtained by combining factors on a two-by-two basis (Bentler \& Bonett, 1980). As can be seen from Table 1, the hypothesized model obtained good fit to the data: $\chi^{2}(41)=56.00, n s, \mathrm{NNFI}=.98$, $\mathrm{CFI}=.98, \mathrm{SRMR}=.05, \mathrm{RMSEA}=.05$. As can also be seen from Table 1, this model outperformed any alternative two-factor model or a one-factor model $(p<.001)$. These results confirm the distinctiveness of our core multi-item constructs. 


\section{Descriptive Statistics and Intercorrelations}

Descriptive statistics and correlations for the study variables are shown in Table 2. Variables had reasonably strong reliability ( $\alpha$ s $>.70$ ). Among correlations, it is worth noting that NA was positively related to emotional exhaustion $(r=.20, p<.05)$, whereas emotional exhaustion was positively related to turnover $(r=.24, p<.01)$. In contrast, the relationships of POS with NA $(r$ $=-.01, n s)$, emotional exhaustion $(r=.06, n s)$, and turnover $(r=-.12, n s)$ were all nonsignificant.

\section{Hypothesis Tests}

In order to test our hypotheses, we first conducted a moderated multiple regression analysis using emotional exhaustion as the dependent variable. Control variables (age, gender, and organizational tenure) were entered at Step 1, followed by the main predictors, POS and NA, which have been centered (Aiken $\&$ West, 1991), at Step 2. Finally, the POS $\times$ NA product term was entered at Step 3. Results are presented in Table 3. Second, as turnover is a binary outcome, we conducted a moderated logistic regression predicting Time 3 turnover. Control variables were entered at Step 1, followed by centered POS and NA, at Step 2. The POS $\times$ NA product term was entered at Step 3, while the presumed mediator between POS and turnover, emotional exhaustion, and the emotional exhaustion $\times$ NA product term, were entered at Step 4 . Results are presented in Table 4 . Tables 3 and 4 provide the necessary information to test our hypotheses. ${ }^{1}$

Hypothesis 1a stated that POS would be negatively related to emotional exhaustion. As can be seen from Table 3, Time 1 POS was unrelated to Time 2 emotional exhaustion $(\beta=.07$, ns; Table 3, Model 2), disconfirming Hypothesis 1a. Next, Hypothesis 1b predicted that emotional exhaustion would be positively related to turnover. As can be seen from Table 4, the relationship between Time 2 emotional exhaustion and Time 3 turnover was indeed significantly positive (B $=2.17, p<.01$; Table 4, Model 4), lending support to Hypothesis 1b. Hypothesis 1c stated that 
emotional exhaustion would mediate a negative relationship between POS and turnover. This was formally tested using a bootstrapping procedure and Preacher and Hayes's (2008) SPSS macro. We estimated the indirect effect of POS on turnover using 1,000 bootstrapped resamples (with replacement) from the full sample, which allowed us to create a bias-corrected confidence interval (CI) for the estimated indirect effect (MacKinnon, Lockwood, \& Williams, 2004).

The bootstrap approach to testing indirect effects is known to overcome the limitations of the Baron and Kenny (1986) method and its associated Sobel test (Sobel, 1982). Basically, Baron and Kenny's approach requires that the independent variable be first shown to be significantly related to the dependent variable. This condition is not correct because "requiring a significant relationship between $X$ and $Y$ in the first step can obscure a mediated effect that is accompanied by a direct effect of opposite sign" (Edwards \& Lambert, 2007, p. 3). Moreover, the Sobel test can provide inaccurate results because it relies on the assumption of a normal distribution for the product of the path coefficients involved in the mediation, an assumption that is oftentimes unsupported (Edwards \& Lambert, 2007). Therefore, a bootstrap approach, which uses the actual sampling distribution of the data to derive CIs for estimated indirect effects, is preferred (MacKinnon, Lockwood, Hoffman, West, \& Sheets, 2002).

To preserve statistical power, we removed control variables (the sample size for this analysis dropped to 112 with the controls included, while it was 126 without the controls). This was further justified by the fact that controls were unrelated to turnover (see Table 4). This analysis revealed that the indirect effect of POS on turnover through Time 2 emotional exhaustion was nonsignificant as the $\mathrm{CI}$ included zero $(.07,95 \% \mathrm{IC}=-.17, .42){ }^{2}$ Thus, Hypothesis $1 \mathrm{c}$ was rejected.

Hypothesis 2a stated that NA would moderate the relationship between POS and emotional exhaustion, this relationship being expected to be stronger and positive when NA is high. As can 
be seen from Table 3 , NA interacted with POS in predicting emotional exhaustion $(\beta=.20, p<$ $.05, \Delta R^{2}=.04$; Table 3, Model 3). To illustrate the nature of this interaction, we plotted the regression line for POS on emotional exhaustion at $1 S D$ below and $1 S D$ above the mean of NA (Aiken \& West, 1991) (see Figure 2). The regression line for Time 1 POS on Time 2 emotional exhaustion was significantly positive when NA was high, $t(111)=2.20, p<.05$, but nonsignificant when NA was low $t(111)=-1.15, n s$. The slopes of these regression lines were also significantly different from one another $t(111)=2.20, p<.05$. Hypothesis $2 \mathrm{a}$ is thus supported.

Hypothesis $2 \mathrm{~b}$ presents a first-stage moderated mediation model (Edwards \& Lambert, 2007) in which NA moderates the indirect relationship between POS and turnover through emotional exhaustion such that this relationship would be expected to be stronger and positive when NA is high. To formally test this hypothesis, we used the same bootstrapping procedure described above (Preacher \& Hayes, 2008). As for the test of Hypothesis 1c presented above, and for the same reasons, we dropped the controls. The indirect effect of POS on turnover through emotional exhaustion was significantly moderated by NA $(.45,95 \% \mathrm{IC}=.04,1.57)$ : as expected, this indirect effect was significant and positive when NA was high $(.34,95 \%$ IC $=.02,1.11)$ but nonsignificant when NA was low $(-.24,95 \% \mathrm{IC}=-1.11, .06) .{ }^{3}$ Hypothesis $2 \mathrm{~b}$ is thus supported.

Hypothesis 3a stated that NA would also moderate the relationship between emotional exhaustion and turnover such that this relationship would be expected to be significantly more positive when NA is low (vs. high). As can be seen from Table 4, emotional exhaustion interacted with NA in predicting turnover $(\mathrm{B}=-2.56, p<.01$; Model 4$)$. To illustrate the nature of this interaction, we used J. F. Dawson's Excel worksheet relative to 2-way interactions in binary logistic regression (http://www.jeremydawson.co.uk/slopes.htm) to plot the relationship between emotional exhaustion and turnover at high and low values of NA. This is represented in 
Figure 3. As can be seen, there is an exponential and steep increase of the effect of emotional exhaustion on turnover after the mid-point of the scale under conditions of low NA, while the effect of emotional exhaustion is slightly positive under conditions of high NA. Further probing of this interaction using a mean-split approach reveals that emotional exhaustion has a significant and positive effect on turnover at below average values of NA $(\mathrm{B}=2.05, p<.01)$ while emotional exhaustion is unrelated to turnover at above average values of NA $(\mathrm{B}=-.38, n s)$. Hypothesis $3 \mathrm{a}$ is thus supported.

Finally, Hypothesis 3b describes a second-stage moderated mediation model (Edwards \& Lambert, 2007) in which NA moderates the indirect relationship between POS and turnover through emotional exhaustion such that this relationship would be expected to be stronger and negative when NA is low. To test this hypothesis, we used the same bootstrapping procedure described above (Preacher \& Hayes, 2008). As for the test of Hypothesis $2 b$, we dropped the controls from this analysis. The index of moderation mediation provided by Preacher and Hayes's macro was however nonsignificant $(-.12,95 \%$ IC $=-1.34, .29)$, indicating that the second-stage moderated mediation model was not supported. Hence, Hypothesis $3 \mathrm{~b}$ is not supported.

\section{Discussion}

This study used a three-wave time-lagged design to examine the relationship between POS, NA, emotional exhaustion, and turnover. Time 1 POS was unrelated to Time 2 emotional exhaustion while the latter was associated with increased turnover at Time 3. Moreover, NA interacted with POS such that the latter was more strongly and positively related to Time 2 emotional exhaustion and indirectly related to increased turnover under high NA conditions. Emotional exhaustion also interacted with NA such that its positive effect on turnover was 
enhanced at low levels of NA. These findings have a number of significant implications for theory and practice that we now discuss in the next sections.

\section{Theoretical Implications and Future Directions}

First, an important result of this study was that POS was unrelated to subsequent emotional exhaustion. This null finding may be caused by a variety of factors such as the reduced sample size, the nature of the sample, or the fact that emotional exhaustion was measured six months after POS, such time-lagged relationship having rarely been examined (Baran et al., 2012). For example, the fact that we used a French version of the POS scale may be at stake in this null finding. Yet, this scale has been validated in previous studies (Panaccio \& Vandenberghe, 2009; Vandenberghe et al., 2004) and found to possess psychometric properties similar to the English version of the scale and to predict with the same magnitude affective organizational commitment, i.e., one of the strongest attitudinal correlate of POS (Rhoades \& Eisenberger, 2002). Another possibility relates to the nature of the sample, which represented a cross-section of organizations and industries, rather than a homogenous sample of employees from the same organizational context. Thus, our results may reflect the confounding influence of organizationor industry-level variables. ${ }^{4}$ Another specific characteristic of our sample is that it comprised on average relatively long-tenured $(M=8.93$ years $)$ and middle-aged $(M=40.31$ years $)$ employees. These employees are likely to be well established in their work role and may thus be less reliant on POS to experience well-being. For example, these employees may find more value in receiving support from co-workers.

There might also be a methodological explanation to the absence of a significant relationship between POS and emotional exhaustion. Figure 2 shows that the interaction between POS and NA on emotional exhaustion is disordinal in nature (Aiken \& West, 1991): among high-NA people, the relationship between POS and emotional exhaustion is significantly positive while 
when NA is low, there is a slight, albeit it nonsignificant, trend towards a negative relationship between these two variables. Thus, on average, the two slopes cancel out each other. This may explain why the overall relationship between POS and emotional exhaustion was nonsignificant. Another factor that may account for this nonsignificant relationship relates to the time lag observed between measurements of POS and emotional exhaustion. It might be that the social resources associated with POS wane out within a shorter period of time, hence cannot reduce the likelihood of experiencing emotional exhaustion at a later time. Obviously, more longitudinal research is needed to clarify this issue.

Second, as mentioned above, an important finding of this study was that POS was positively related to emotional exhaustion when NA was high. Actually, as NA reflects a lack of personal resources, hence represents a weakness factor when it comes to predict individuals' reactions to stress (e.g., Cordes \& Dougherty, 1993; Ng \& Sorensen, 2009), its role as a moderator of POS is particularly insightful. Indeed, research has barely considered that POS does not operate in a vacuum and could be affected by individuals' dispositions. NA is a well-known personality trait (Thoresen et al., 2003; Watson, 1988; Watson et al., 1988) that involves a pessimistic perception of the environment (Bowling et al., 2008; Weiss \& Cropanzano, 1996). We advocated that NA influences how POS is perceived and that high-NA individuals would infer from indications of support received that the organization has high expectations towards them. In other words, they would perceive the organization's support as a demand rather than as a resource. This may account for the positive relationship between POS and emotional exhaustion under high NA conditions.

Third, this study breaks new ground by probing into the complex articulation between social resources (POS) and personal resources, or lack thereof (NA). However, our study only scratched the surface of the dynamics between social and personal resources. COR theory states 
that a lack of resources leads to defensive attempts to conserve remaining resources (Halbesleben, Neveu, Paustian-Underdahl, \& Westman, 2014; Hobfoll, 2001). Halbesleben and colleagues describe these attempts as a reaction to resource loss. Nonetheless, COR theory remains mute regarding how people deal with a dispositional tendency to experience and/or perceive resource loss, as exemplified by high levels of NA. In fact, little is known about the effect of a lack of personal resources that has a dispositional basis. Hobfoll (2001, p. 348) stated however that a "chronic lack of resources [...] makes people more vulnerable to resources loss", suggesting that people with high NA should suffer more readily from resource loss. Besides the dispositional basis (e.g., NA) of the perception of resource loss, one may wonder whether all forms of support generated by POS would interact with NA. Indeed, POS may cover socioemotional, instrumental, or informational resources. Yet, it is unclear whether these resources have the same salience to individuals and would interact with NA. It might also be that the effect of resource loss on psychological well-being is contingent upon the specific resource at stake (Morelli \& Cunningham, 2012).

Finally, this study found a compensatory interaction between emotional exhaustion and NA in predicting turnover. Actually, emotional exhaustion was more strongly and positively related to turnover when NA was low. However, one should note that this interaction did not influence the indirect relationship between POS and turnover through emotional exhaustion. This interaction is nonetheless interesting because it suggests that NA and emotional exhaustion act as comparable mechanisms of withdrawal that serve self-protective purposes (Cole \& Bedeian, 2007; Maslach et al., 2001; Swider \& Zimmerman, 2010; Thoresen et al. 2003; Wright \& Cropanzano, 1998; Zimmerman, 2008). Therefore, one of the two variables would be sufficient to engender turnover. Our findings tend to support this view. Indeed, both NA and emotional exhaustion were positively associated with turnover in the final logistic regression model $(\mathrm{B}=$ 
2.93, $p<.05$, and $\mathrm{B}=2.17, p<.01$, respectively; Table 4, Model 4). Following this logic, it makes perfect sense that emotional exhaustion was more strongly related to turnover at low levels of NA.

The above findings have important implications for how COR as a stress management theory really works. Research on COR theory suggested that psychological resources, either personal or social (Hobfoll, 2002; Hobfoll \& Lilly, 1993; Morelli \& Cunningham, 2012), would help individuals to cope with stressful job conditions and get additional resources to complete job duties. What the present study adds to these principles is that POS as a specific social resource does not represent a universal resource for all individuals. High-NA individuals may actually perceive support from the organization as an organizational demand rather than an organizational resource. Thus, resources such as POS may be in the eye of the beholder, suggesting that it is the appraisal of a given characteristic that makes a presumptive resource resourceful vs. demanding (Lazarus \& Folkman, 1984). COR theory principles might thus be interpreted in light of individuals' appraisal tendencies. As a result, it might be as important for organizations to provide resources to their employees as to act on how employees perceive them. Therefore, communication efforts targeting the organization's sincerity and genuineness in providing valuable resources to employees are particularly important.

In terms of future research avenues, it is worth mentioning that this study did not include affective organizational commitment, which is a well-known mediator of the relationship between POS and turnover (Rhoades, Eisenberger, \& Armeli, 2001; Stinglhamber \& Vandenberghe, 2003). It is important to note however that affective commitment and emotional exhaustion may, at least partially, characterize a situation of competitive mediation (Zhao, Lynch, \& Chen, 2010). Competitive mediation describes a situation where the two mediators point in opposite directions (affective commitment mediating a negative relationship with 
turnover, and emotional exhaustion mediating a positive relationship with turnover among highNA individuals). It is precisely the reason why one cannot rely on the nature and strength of the relationship between POS and turnover to infer that there is an "effect to be mediated" (Zhao et al., 2010, p. 199), as this relationship may be weakened by the presence of the two competitive mediators. On a different note, as discussed above, it is likely that different personal resources such as self-esteem, material resources, or emotional resources, among others, have different effects on resource loss. It would be worth investigating the unique effects of these distinctive personal resources. Finally, although resource loss was theorized to be the central process through which emotional exhaustion occurred, we did not formally assess such loss. Future research should measure this psychological variable more directly.

\section{Limitations}

This study has several limitations that should be acknowledged. First, the sample size for analyses was relatively small. The present results should thus be replicated on larger and diversified samples of employees. Second, the overall response rate for the study was quite low $(12 \%)$. Yet, there was no evidence that this low response rate was affected by attrition (systematic) bias across time (see attrition analysis results in the Method section). Third, although our study was based on a three-wave time-lagged design, the study was not truly longitudinal. Thus, it would be advisable to use panel designs in the future in order to track individuals' POS and emotional exhaustion across time and examine if and how the change trajectories of these variables relate to one another (Ployhart \& Vandenberg, 2010).

\section{Practical Implications}

From a practical perspective, this study yielded results that have important implications. First, as POS was unrelated to emotional exhaustion and as the latter predicted subsequent turnover behavior, organizations should think of finding ways to prevent resource loss from 
occurring among their employees. This can be done through implementing strategies or practices that will help them to have access to the larger social network within the organization (i.e., coworkers from the same department or other departments, but also supervisors). These sources of social support could supplement support from the organization (which was ineffective in this study) and save employees from experiencing or perceiving resource loss and leaving as a result. Second, concrete actions can be made by organizations to counteract the detrimental interaction between POS and NA on emotional exhaustion. More precisely, as we suggested that high-NA individuals may actually interpret the actions leading up to POS in negative terms (i.e., as suggesting that the organization has no genuine support but rather expects a lot in terms of return from the employees it supports), organizations would be well advised to provide concrete indications to employees that its supportive actions are generated out of benevolent intentions (Eisenberger, Cummings, Armeli, \& Lynch, 1997). Moreover, clarifying the organization's actual expectations of return from employees could emphasize procedural justice, which should build positive employee-organization relationships (Colquitt et al., 2013).

\section{Conclusion}

In conclusion, this study contributes to extend our knowledge of how personal and social resources influence resource depletion and turnover. First, it is shown that NA is an important moderator of the effects of POS and emotional exhaustion. Second, it appears that POS is experienced as a taxing work demand (rather than as a resource) among individuals with high levels of NA. Finally, turnover was predictable from the combined influences of POS, emotional exhaustion, and NA. We hope the present results will encourage future research endeavors at looking at the interplay of social and personal resources and how these resources affect the turnover process. 


\section{References}

Abraham, R. (1999). Negative affectivity: Moderator or confound in emotional dissonanceoutcome relationships? Journal of Psychology, 133, 61-72.

Aiken, L. S., \& West, S. G. (1991). Multiple regression: Testing and interpreting interactions. Thousand Oaks, CA: Sage.

Allen, D. G., \& Shanock, L. R. (2013). Perceived organizational support and embeddedness as key mechanisms connecting socialization tactics to commitment and turnover among new employees. Journal of Organizational Behavior, 34, 350-369.

Allen, D. G., Shore, L. M., \& Griffeth, R. W. (2003). The role of perceived organizational support and supportive human resource practices in the turnover process. Journal of Management, 29, 99-118.

Armeli, S., Eisenberger, R., Fasolo, P., \& Lynch, P. (1998). Perceived organizational support and police performance: The moderating influence of socioemotional needs. Journal of Applied Psychology, 83, 288-297.

Armstrong-Stassen, M. (2004). The influence of prior commitment on the reactions of layoff survivors to organizational downsizing. Journal of Occupational Health Psychology, 9, 4660.

Baran, B. E., Shanock, L. R., \& Miller, L. R. (2012). Advancing organizational support theory into the twenty-first century world of work. Journal of Business and Psychology, 27, 123147.

Baron, R. M., \& Kenny, D. A. (1986). The moderator-mediator variable distinction in social psychological research: Conceptual, strategic, and statistical considerations. Journal of Personality and Social Psychology, 5, 1173-1182. 
Barsade, S. G., Brief, A. P., \& Spataro, S. E. (2003). The affective revolution in organizational behavior: The emergence of a paradigm. In J. Greenberg (Ed.), Organizational behavior: The state of the science (2nd ed.) (pp. 3-51). Hillsdale, NJ: Lawrence Erlbaum.

Bentler, P. M., \& Bonett, D., G. (1980). Significante tests and goodness of fit in the analysis of covariance structures. Psychological Bulletin, 88, 588-606.

Blau, P. (1964). Exchange and power in social life. New York: Wiley.

Bowling, N. A., Hendricks, E. A., \& Wagner, S. H. (2008). Positive and negative affectivity and facet satisfaction: A meta-analysis. Journal of Business and Psychology, 23, 115-125.

Bradley, G. (2007). Job tenure as a moderator of stressor-strain relations: A comparison of experienced and new-start teachers. Work and Stress, 21, 48-64.

Cole, M. S., \& Bedeian, A. G. (2007). Leadership consensus as a cross-level contextual moderator of the emotional exhaustion-work commitment relationship. Leadership Quarterly, 18, 447-462.

Colquitt, J. A., Scott, B. A., Rodell, J. B., Long, D. M., Zapata, C. P., Conlon, D. E., \& Wesson, M. J. (2013). Justice at the millennium, a decade later: A meta-analytic test of social exchange and affect-based perspectives. Journal of Applied Psychology, 98, 199-236.

Connolly, J. J., \& Viswesvaran, C. (2000). The role of affectivity in job satisfaction: A metaanalysis. Personality and Individual Differences, 29, 265-281.

Cordes, C. L., \& Dougherty, T. W. (1993). A review and an integration of research on job burnout. Academy of Management Review, 18, 621-656.

Crawford, E. R., LePine, J. A., \& Rich, B. L. (2010). Linking job demands and resources to employee engagement and burnout: A theoretical extension and meta-analytic test. Journal of Applied Psychology, 95, 834-848. 
Cropanzano, R., \& Mitchell, M. S. (2005). Social exchange theory: An interdisciplinary review. Journal of Management, 31, 874-900.

Dawley, D., Houghton, J. D., \& Bucklew, N. S. (2010). Perceived organizational support and turnover intention: The mediating effects of personal sacrifice and job fit. Journal of Social Psychology, 150, 238-257.

Edwards, J. R., \& Lambert, L. S. L. (2007). Methods for integrating moderation and mediation: A general analytical framework using moderated path analysis. Psychological Methods, 12, $1-22$.

Eisenberger, R., Cummings, J., Armeli, S., \& Lynch, P. (1997). Perceived organizational support, discretionary treatment, and job satisfaction. Journal of Applied Psychology, 82, $812-820$.

Eisenberger, R., Huntington, R., Hutchison, S., \& Sowa, D. (1986). Perceived organizational support. Journal of Applied Psychology, 71, 500-507.

Eisenberger, R., Stinglhamber, F., Vandenberghe, C., Sucharski, I., \& Rhoades, L. (2002). Perceived supervisor support: Contributions to perceived organizational support and employee retention. Journal of Applied Psychology, 87, 565-573.

Goodman, J. S., \& Blum, T. C. (1996). Assessing the non-random sampling effects of subject attrition in longitudinal research. Journal of Management, 22, 627-652.

Griffeth, R. W., Hom, P. W., \& Gaertner, S. (2000). A meta-analysis of antecedents and correlates of employee turnover: Update, moderator tests, and research implications for the next millennium. Journal of Management, 26, 463-488.

Halbesleben, J. R. B. (2006). Sources of social support and burnout: A meta-analytic test of the conservation of resources model. Journal of Applied Psychology, 91, 1134-1145. 
Halbesleben, J. R. B., Neveu, J.-P., Paustian-Underdahl, S. C., \& Westman, M. (2014). Getting to the "COR": Understanding the role of resources in conservation of resources theory. Journal of Management, 40, 1334-1364.

Harris, R. B., Harris, K. J., \& Harvey, P. (2007). A test of competing models of the relationships among perceptions of organizational politics, perceived organizational support, and individual outcomes. Journal of Social Psychology, 147, 631-655.

Hobfoll, S. E. (1988). The ecology of stress. Washington, DC: Hemisphere Publishing Corp. Hobfoll, S. E. (1989). Conservation of resources: A new attempt at conceptualizing stress. American Psychologist, 44, 513-524.

Hobfoll, S. E. (2001). The influence of culture, community, and the nested-self in the stress process: Advancing conservation of resources theory. Applied Psychology: An International Review, 50, 337-369.

Hobfoll, S. E. (2002). Social and psychological resources and adaptation. Review of General Psychology, 6, 307-324.

Hobfoll, S. E. (2011). Commentary. Conservation of resource caravans and engaged settings. Journal of Occupational and Organizational Psychology, 84, 116-122.

Hobfoll, S. E., Freedy, J., Lane, C., \& Geller, P. (1990). Conservation of social resources: Social support resource theory. Journal of Social and Personal Relationships, 7, 465-478.

Hobfoll, S. E., \& Lilly, R. S. (1993). Resource conservation as a strategy for community psychology. Journal of Community Psychology, 21, 128-148.

Hobfoll, S. E., \& Stokes, J. P. (1988). The process and mechanism of social support. In S. W. Duck (Ed.), The handbook of research in personal relationships (pp. 497-517). London: Wiley. 
Hochwarter, W. A., Kacmar, C., Perrewe, P. L., \& Johnson, D. (2003). Perceived organizational support as a mediator of the relationship between politics perceptions and work outcomes. Journal of Vocational Behavior, 63, 438-456.

Hochwarter, W. A., Perrewé, P. L., Hall, A. T., \& Ferris, G. R. (2005). Negative affectivity as a moderator of the form and magnitude of the relationship between felt accountability and job tension. Journal of Organizational Behavior, 26, 517-534.

Holahan, C. J., Moos, R. H., Holahan, C. K., \& Cronkite, R. C. (1999). Resource loss, resource gain, and depressive symptoms: A 10-year model. Journal of Personality and Social Psychology, 77, 620-629.

Ilies, R., Dimotakis, N., \& De Pater, I. E. (2010). Psychological and physiological reactions to high workloads: Implications for well-being. Personnel Psychology, 63, 407-436.

Iverson, R. D., Olekalns, M., \& Erwin, P. J. (1998). Affectivity, organizational stressors, and absenteeism: A causal model of burnout and its consequences. Journal of Vocational Behavior, 52, 1-23.

Jawahar, I. M., Stone, T. H., \& Kisamore, J. L. (2007). Role conflict and burnout: The direct and moderating effects of political skill and perceived organizational support on burnout dimensions. International Journal of Stress Management, 14, 142-159.

Johnson, R. E., Groff, K. W., \& Taing, M. U. (2009). Nature of the interactions among organizational commitments: Non-existent, competitive, or synergistic? British Journal of Management, 20, 431-447.

Jöreskog, K. G., Sörbom, D., Du Toit, S., \& Du Toit, M. (2001). LISREL 8: New statistical features. Chicago, IL: Scientific Software International. 
Lapointe, E., Vandenberghe, C., \& Panaccio, A. (2011). Organizational commitment, organization-based self-esteem, emotional exhaustion, and turnover: A conservation of resources perspective. Human Relations, 64, 1609-1631.

Lazarus, R. S., \& Folkman, S. (1984). Stress, appraisal, and coping. New York: Springer.

Lee, R. T., \& Ashforth, B. E. (1996). A meta-analytic examination of the correlates of the three dimensions of job burnout. Journal of Applied Psychology, 81, 123-133.

Little, T. D., Cunningham, W. A., Shahar, G., \& Widaman, K. F. (2002). To parcel or not to parcel: Exploring the question, weighing the merits. Structural Equation Modeling, 9, 151173.

Loi, R., Hang-Yue, N., \& Foley, S. (2006). Linking employees' justice perceptions to organizational commitment and intention to leave: The mediating role of perceived organizational support. Journal of Occupational and Organizational Psychology, 79, 101120.

Mackey, J. D., \& Perrewe, P. L. (2014). The AAA (appraisals, attributions, adaptation) model of job stress: The critical role of self-regulation. Organizational Psychology Review, 4, 258 278.

MacKinnon, D. P., Lockwood, C. M., Hoffman, J. M., West, S. G., \& Sheets, V. (2002). A comparison of methods to test mediation and other intervening variable effects. Psychological Methods, 7, 83-104.

MacKinnon, D. P., Lockwood, C. M., \& Williams, J. (2004). Confidence limits for the indirect effect: Distribution of the product and resampling methods. Multivariate Behavioral Research, 39, 99-123.

Maertz, C. P., Griffeth, R. W. (2004). Eight motivational forces and voluntary turnover: A theoretical synthesis with implications for research. Journal of Management, 30, 667-683. 
Maertz, C. P., Jr., Griffeth, R. W., Campbell, N. S., \& Allen, D. G. (2007). The effects of perceived organizational support and perceived supervisor support on employee turnover. Journal of Organizational Behavior, 28, 1059-1075.

Maslach, C., Schaufeli, W. B., \& Leiter, M. P. (2001). Job burnout. Annual Review of Psychology, 52, 397-422.

Morelli, N. A., \& Cunningham, C. J. L. (2012). Not all resources are created equal: COR theory, values, and stress. Journal of Psychology, 146, 393-415.

Ng, T. W. H., \& Sorensen, K., L. (2009). Dispositional affectivity and work-related outcomes: A meta-analysis. Journal of Applied Social Psychology, 39, 1255-1287.

O’Neill, O. A., Vandenberg, R. J., Dejoy, D. M., \& Wilson, M. G. (2009). Exploring relationships among anger, perceived organizational support, and workplace outcomes. Journal of Occupational Health Psychology, 14, 318-333.

Panaccio, A., \& Vandenberghe, C. (2009). Perceived organizational support, organizational commitment and psychological well-being: A longitudinal study. Journal of Vocational Behavior, 75, 224-236.

Panaccio, A., Vandenberghe, C., \& Ben Ayed, A. K. (2014). The role of negative affectivity in the relationships between pay satisfaction, affective and continuance commitment, and voluntary turnover: A moderated mediation model. Human Relations, 67, 821-848.

Ployhart, R. E., \& Vandenberg, R. J. (2010). Longitudinal research: The theory, design, and analysis of change. Journal of Management, 36, 94-120.

Podsakoff, P. M., MacKenzie, S. B., \& Podsakoff, N. P. (2012). Sources of method bias in social science research and recommendations on how to control it. Annual Review of Psychology, $63,539-569$. 
Preacher, K. J., \& Hayes, A. F. (2008). Asymptotic and resampling strategies for assessing and comparing indirect effects in multiple mediator models. Behavior Research Methods, 40, 879-891.

Rhoades, L., \& Eisenberger, R. (2002). Perceived organizational support: A review of the literature. Journal of Applied Psychology, 87, 698-714.

Rhoades, L., Eisenberger, R., \& Armeli, S. (2001). Affective commitment to the organization: The contribution of perceived organizational support. Journal of Applied Psychology, 86, $825-836$.

Riggle, R. J., Edmondson, D. R., \& Hansen, J. D. (2009). A meta-analysis of the relationship between perceived organizational support and job outcomes: 20 years of research. Journal of Business Research, 62, 1027-1030.

Schaufeli, W. B., Leiter, M. P., Maslach, C., \& Jackson, S. E. (1996). The MBI-General Survey. In C. Maslach, S. E. Jackson, \& M. P. Leiter (Eds.), Maslach Burnout Inventory Manual (3d ed.) (pp.19-26). Palo Alto, CA: Consulting Psychologists Press.

Sluss, D. M., Klimchak, M., \& Holmes, J. J. (2008). Perceived organizational support as a mediator between relational exchange and organizational identification. Journal of Vocational Behavior, 73, 457-464.

Sobel, M. E. (1982). Asymptotic confidence intervals for indirect effects in structural equation models. In S. Leinhart (Ed.), Sociological methodology 1982 (pp. 290-312). San Francisco: Jossey-Bass.

Spector, P. E., Zapf, D., Chen, P. Y., \& Frese, M. (2000). Why negative affectivity should not be controlled in job stress research: Don't throw out the baby with the bath water. Journal of Organizational Behavior, 21, 79-95. 
Stinglhamber, F., \& Vandenberghe, C. (2003). Organizations and supervisors as sources of support and targets of commitment: A longitudinal investigation. Journal of Organizational Behavior, 24, 251-270.

Stinglhamber, F., \& Vandenberghe, C. (2004). Favorable job conditions and perceived support: The role of organizations and supervisors. Journal of Applied Social Psychology, 34, 14701493.

Stoeva, A. Z., Chiu, R. K., \& Greenhaus, J. H. (2002). Negative affectivity, role stress, and work-family conflict. Journal of Vocational Behavior, 60, 1-16.

Swider, B. W., \& Zimmerman, R. D. (2010). Born to burnout: A meta-analytic path model of personality, job burnout, and work outcomes. Journal of Vocational Behavior, 76, 487-506.

Thoresen, C. J., Kaplan, S. A., Barsky, A. P., de Chermont, K., \& Warren, C. R. (2003). The affective underpinnings of job perceptions and attitudes: A meta-analytic review and integration. Psychological Bulletin, 129, 914-945.

Vandenberghe, C., Bentein, K., \& Stinglhamber, F. (2004). Affective commitment to the organization, supervisor, and work group: Antecedents and outcomes. Journal of Vocational Behavior, 64, 47-71.

Watson, D. (1988). Intraindividual and interindividual analyses of postive and negative affect: Their relation to health complaints, perceived stress, and daily activities. Journal of Personality and Social Psychology, 54, 1020-1030.

Watson, D., \& Clark, L. A. (1984). Negative affectivity: The disposition to experience aversive emotional states. Psychological Bulletin, 96, 465-490.

Watson, D., Clark, L. A., \& Tellegen, A. (1988). Development and validation of brief measures of positive and negative affect: The PANAS scales. Journal of Personality and Social Psychology, 56, 1063-1070. 
Watson, D., \& Pennebaker, J. W. (1989). Health complaints, stress, and distress: Exploring the central role of negative affectivity. Psychological Review, 96, 234-254.

Watson, D., Wiese, D., Vaidya, J., \& Tellegen, A. E. (1999). The two general activation systems of affect: Structural findings, evolutionary considerations, and psychobiological evidence. Journal of Personality and Social Psychology, 76, 820-838.

Weiss, H. M., \& Cropanzano, R. (1996). Affective events theory: A theoretical discussion of the structure, causes, and consequences of affective experiences at work. Research in Organizational Behavior, 18, 1-74.

Whitman, M. V., Halbesleben, J. R. B., \& Holmes, O. (2014). Abusive supervision and feedback avoidance: The mediating role of emotional exhaustion. Journal of Organizational Behavior, 35, 38-53.

Wong, Y.-T., Wong, C.-S., \& Ngo, H.-Y. (2012). The effects of trust in organization and perceived organizational support on organizational citizenship behavior: A test of three competing models. International Journal of Human Resource Management, 23, 278-293.

Wright, T. A., \& Cropanzano, R. (1998). Emotional exhaustion as a predictor of job performance and voluntary turnover. Journal of Applied Psychology, 83, 486-493.

Zhao, X., Lynch, J. G. Jr., \& Chen, Q. (2010). Reconsidering Baron and Kenny: Myths and truths about mediation analysis. Journal of Consumer Research, 37, 197-206.

Zimmerman, R. D. (2008). Understanding the impact of personality traits on individuals' turnover decisions: A meta-analytic path model. Personnel Psychology, 61, 309-348. 


\section{Footnotes}

${ }^{1}$ Note that the regression results related to our hypotheses, as displayed in Tables 3 and 4, remained roughly similar when control variables were dropped. For example, the POS $\times$ NA product term was significant $(\beta=.22, p<.05)$ (Table 3$)$, while emotional exhaustion $(\mathrm{B}=1.31$, $p<.01)$ and the emotional exhaustion $\times \mathrm{NA}$ product term $(\mathrm{B}=-1.85, p<.01)$ were significant (Table 4), when the controls were dropped.

${ }^{2}$ The indirect effect of POS on turnover through Time 2 emotional exhaustion was also nonsignificant when control variables (age, gender, and tenure) were included $(.10,95 \%$ IC = $-.35,1.53)$.

${ }^{3}$ It should be noted that the indirect effect of POS on turnover through Time 2 emotional exhaustion was not significantly moderated by NA when control variables (age, gender, and tenure) were included $(.60,95 \%$ IC $=-.12,3.25)$, which we attribute to the fact that the sample size dropped significantly (from 126 to 112) with the inclusion of controls, resulting in reduced power to detect effects on an outcome (turnover) with an uneven distribution of scores. The exclusion of controls is further justified by the fact that these variables were unrelated to turnover in logistic regression results (Table 4).

${ }^{4}$ We thank an anonymous reviewer for suggesting this possibility. 
Table 1

Confirmatory Factor Analysis of Measurement Models: Fit Indices

\begin{tabular}{|c|c|c|c|c|c|c|c|c|}
\hline Model & $\chi^{2}$ & $d f$ & $\Delta \chi^{2}$ & $\Delta d f$ & NNFI & CFI & SRMR & RMSEA \\
\hline 1. Hypothesized three-factor model & 56.00 & 41 & - & - & .98 & .98 & .05 & .05 \\
\hline \multicolumn{9}{|l|}{ 2. Two-factor models } \\
\hline Combining POS and NA & $352.01 *$ & 43 & $296.01 *$ & 2 & .58 & .67 & .18 & .21 \\
\hline Combining NA and emotional exhaustion & $258.39 *$ & 43 & $202.39 *$ & 2 & .71 & .77 & .15 & .19 \\
\hline 3. One-factor model & $549.08 *$ & 44 & $493.08 *$ & 3 & .33 & .47 & .22 & .27 \\
\hline
\end{tabular}

Note $. N=133$. POS $=$ Perceived organizational support; NA = Negative affectivity; $d f=$ degrees of freedom; NNFI $=$ nonnormed fit index CFI = comparative fit index; SRMR = standardized root mean square residual; RMSEA = root mean square error of approximation.

$* p<.01$. 
Table 2

Descriptive Statistics and Correlations among Variables

\begin{tabular}{|c|c|c|c|c|c|c|c|c|c|}
\hline 1. Age (years) (T1) & 40.31 & 9.60 & - & & & & & & \\
\hline 2. Gender (T1) & 0.35 & 0.48 & -.02 & - & & & & & \\
\hline 3. Organizational tenure (years) (T1) & 8.93 & 6.95 & $.48 * *$ & .11 & - & & & & \\
\hline 5. NA (T1) & 2.02 & 0.67 & $-.26 * *$ & -.08 & $-.37 * *$ & -.01 & $(.88)$ & & \\
\hline 6. Emotional exhaustion (T2) & 2.29 & 0.96 & -.14 & -.12 & $-.28 * *$ & .06 & $.20 *$ & $(.87)$ & \\
\hline 7. Turnover (T3) & 0.07 & 0.26 & .03 & .06 & -.03 & -.12 & .09 & $.24 * *$ & - \\
\hline
\end{tabular}

Note. Ns $=113-135 . \mathrm{POS}=$ Perceived organizational support; $\mathrm{NA}=$ Negative affectivity; $\mathrm{T} 1=$ Time 1 ; $\mathrm{T} 2=$ Time

2; T3 = Time 3. For Gender: $0=$ female, $1=$ male; for Turnover: $0=$ stayers, $1=$ leavers. Reliability coefficients are reported in parentheses on the diagonal.

$* p<.05 ; * * p<.01$ 
Table 3

Results of Moderated Multiple Regression Analysis for Time 2 Emotional Exhaustion

\begin{tabular}{|c|c|c|c|c|}
\hline Step & Variable(s) entered & Model 1 & Model 2 & Model 3 \\
\hline \multirow[t]{3}{*}{1} & Age (years) (T1) & -.06 & -.08 & -.09 \\
\hline & Gender (T1) & -.08 & -.08 & -.07 \\
\hline & Organizational tenure (years) (T1) & $-.25^{*}$ & -.20 & -.20 \\
\hline \multirow[t]{2}{*}{2} & POS (T1) & & .07 & .08 \\
\hline & NA (T1) & & .13 & .13 \\
\hline \multirow[t]{2}{*}{3} & $\mathrm{POS} \times \mathrm{NA}$ & & & $.20 *$ \\
\hline & $\Delta R^{2}$ & .03 & .04 & $.04 *$ \\
\hline
\end{tabular}

Note. $N=112$. POS $=$ Perceived organizational support; $\mathrm{NA}=$ Negative affectivity; $\mathrm{T} 1=$ Time 1 . For

Gender: $0=$ female, $1=$ male. Except for the $\Delta R^{2}$ row, entries are standardized regression coefficients.

$* p<.05$. 
Table 4

Results of Moderated Logistic Regression Analysis for Turnover

\begin{tabular}{|c|c|c|c|c|c|c|c|c|c|}
\hline \multirow[b]{2}{*}{ Step } & \multirow[b]{2}{*}{ Variable(s) entered } & \multicolumn{2}{|c|}{ Model 1} & \multicolumn{2}{|c|}{ Model 2} & \multicolumn{2}{|c|}{ Model 3} & \multicolumn{2}{|c|}{ Model 4} \\
\hline & & $\mathrm{B}$ & $\operatorname{Exp}(B)$ & $\mathrm{B}$ & $\operatorname{Exp}(B)$ & $\mathrm{B}$ & $\operatorname{Exp}(B)$ & $\mathrm{B}$ & $\operatorname{Exp}(B)$ \\
\hline \multirow[t]{3}{*}{1} & Age (years) (T1) & .03 & 1.03 & .06 & 1.06 & .05 & 1.05 & .11 & 1.12 \\
\hline & Gender (T1) & .14 & 1.15 & .31 & 1.36 & .27 & 1.31 & .88 & 2.41 \\
\hline & Organizational tenure (years) (T1) & -.04 & 0.97 & -.04 & 0.96 & -.04 & 0.97 & .07 & 1.07 \\
\hline \multirow[t]{2}{*}{2} & POS (T1) & & & -.57 & 0.57 & -.60 & 0.55 & -.83 & 0.44 \\
\hline & NA $(T 1)$ & & & .43 & 1.54 & .50 & 1.64 & $2.93 *$ & 18.80 \\
\hline 3 & $\mathrm{POS} \times \mathrm{NA}$ & & & & & .56 & 1.75 & .36 & 1.43 \\
\hline \multirow[t]{3}{*}{4} & Emotional exhaustion (T2) & & & & & & & $2.17 * *$ & 8.77 \\
\hline & Emotional exhaustion $\times \mathrm{NA}$ & & & & & & & $-2.56^{* *}$ & 0.08 \\
\hline & $R^{2}$ & .01 & & .06 & & .07 & & .49 & \\
\hline
\end{tabular}

Note. $N=112$. POS $=$ Perceived organizational support; NA = Negative affectivity; $\mathrm{T} 1=$ Time $1 ; \mathrm{T} 2=$ Time 2 . For Gender: $0=$ female, $1=$ male. The $R^{2}$ row includes Nagelkerke $R^{2}$ values. Final model statistics: $\chi^{2}(8)=24.61, p<.01,-2 \mathrm{LL}=33.03$, constant $=$ -4.60. Nagelkerke $R^{2}=.49$.

$* p<.05$; ** $p<.01$. 


\section{Figure Captions}

Figure 1. Theoretical model for the study.

Figure 2. Interaction between Time 1 POS and T1 NA in predicting Time 2 emotional exhaustion.

Figure 3. Interaction between Time 2 Emotional exhaustion and T1 NA in predicting Time 3 Turnover. 


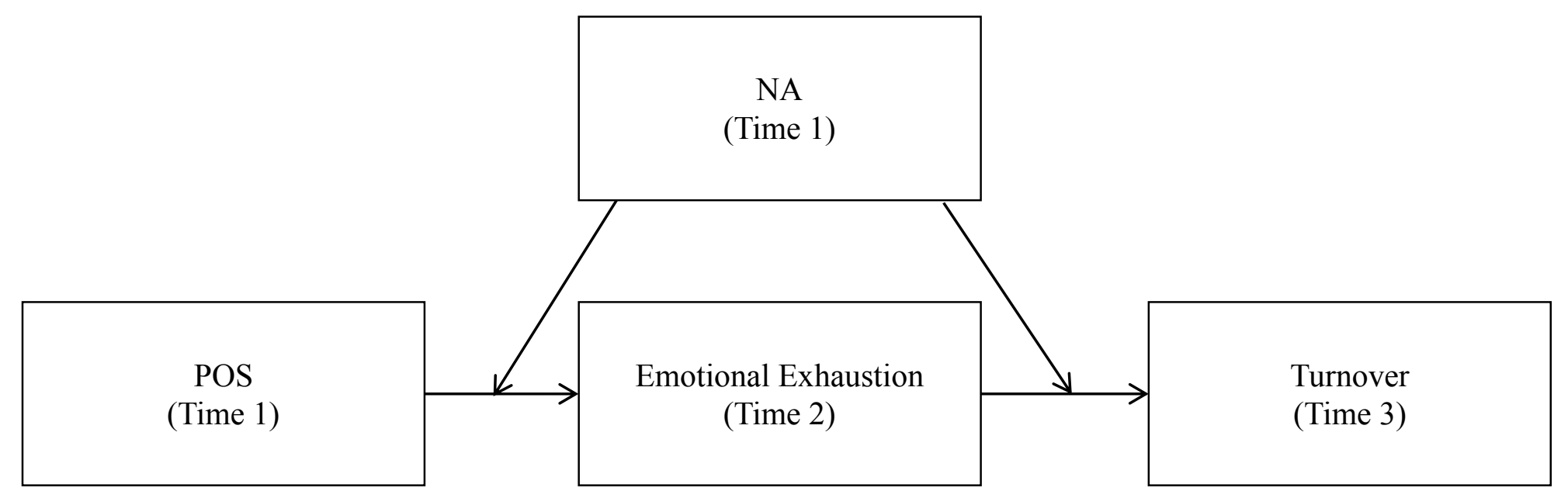




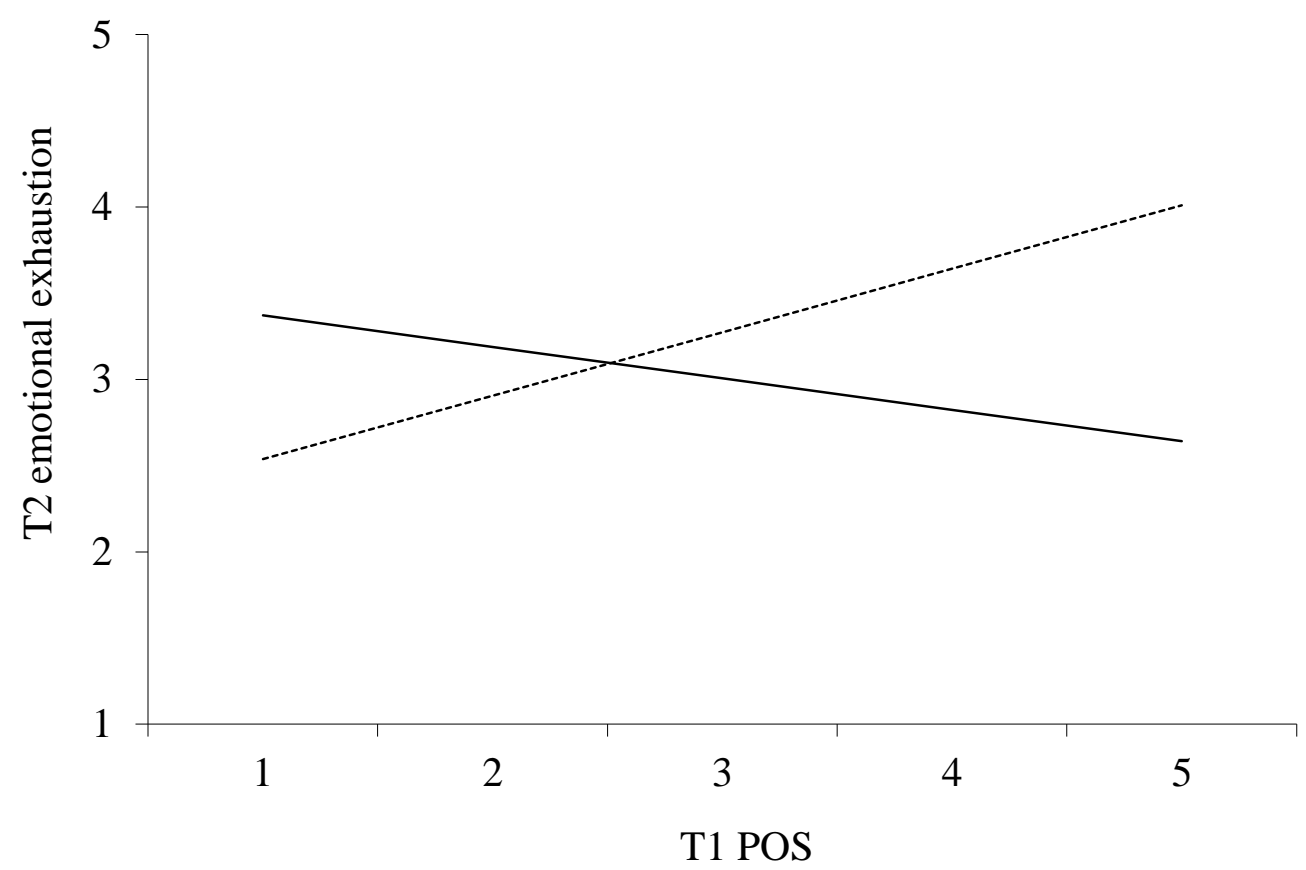

High T1 NA Low T1 NA 


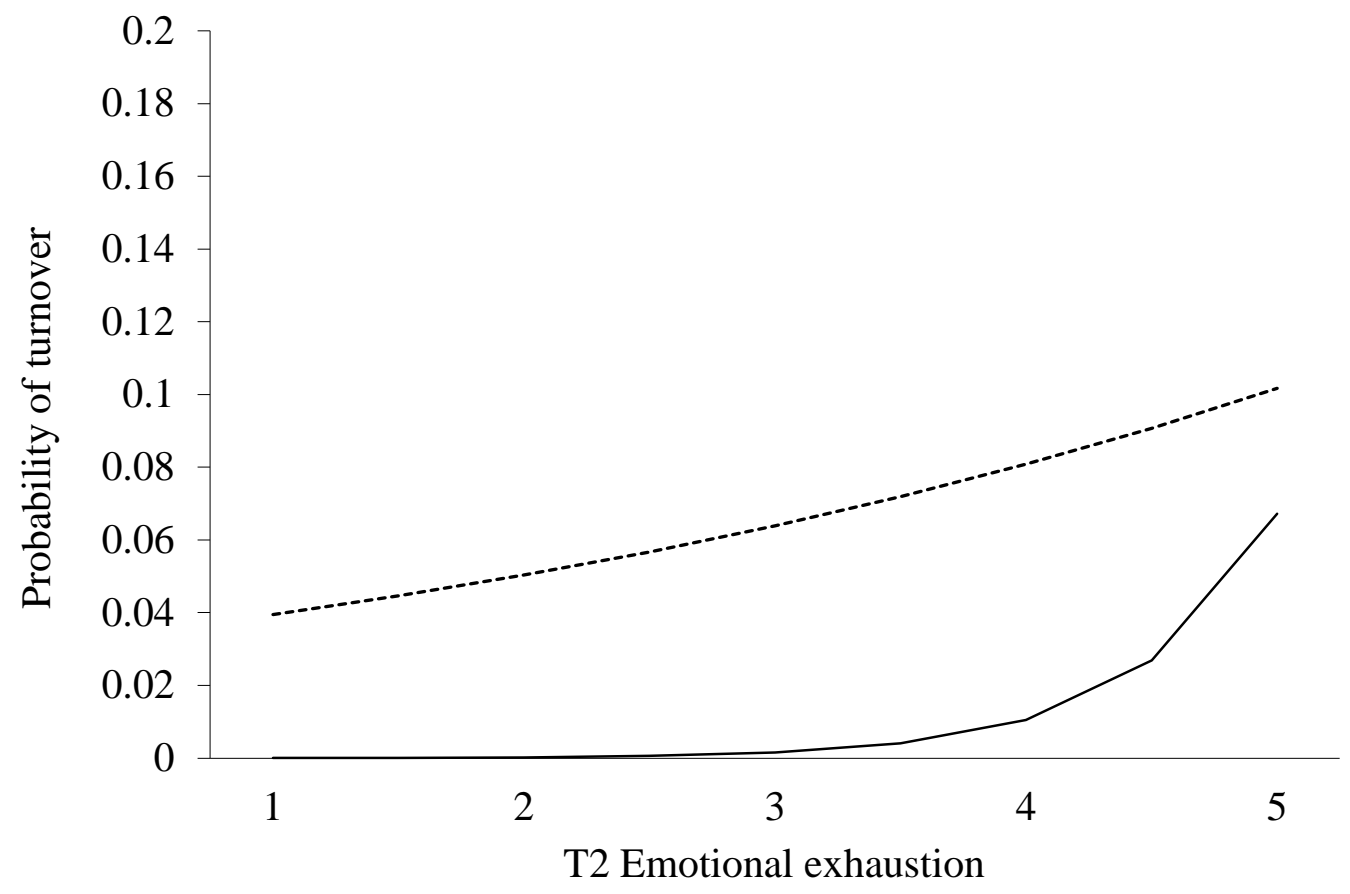

— Low NA ------ High NA 